\title{
Evaluation of Efficacy of Low-Level Laser Therapy
}

\author{
Vahid Mansouri' ${ }^{1}$, Babak Arjmand ${ }^{2}$, Mostafa Rezaei Tavirani ${ }^{1 *}$, Mohammadreza Razzaghi ${ }^{3}$, Mohammad \\ Rostami-Nejad ${ }^{4}$, Mostafa Hamdieh ${ }^{5}$
}

'Proteomics Research Center, Faculty of Paramedical Sciences, Shahid Beheshti University of Medical Sciences, Tehran, Iran ${ }^{2}$ Cell Therapy and Regenerative Medicine Research Center, Endocrinology and Metabolism Molecular-Cellular Sciences Institute, Tehran University of Medical Sciences, Tehran, Iran

${ }^{3}$ Laser Application in Medical Sciences Research Center, Shahid Beheshti University of Medical Sciences, Tehran, Iran

${ }^{4}$ Gastroenterology and Liver Diseases Research Center, Research Institute for Gastroenterology and Liver Diseases, Shahid Beheshti University of Medical Sciences, Tehran, Iran

${ }^{5}$ Department of Psychosomatic, Taleghani Hospital, Faculty of Medicine, Shahid Beheshti University of Medical Sciences, Tehran, Iran

\section{*Correspondence to Mostafa Rezaei Tavirani, Email: tavirany@yahoo.com \\ Published online October 3 , 2020}

\begin{abstract}
Introduction: Given the inconsistencies in the literature regarding laser performance in nonsurgical treatments, this study investigated the available literature to determine the advantages and disadvantages of low-power lasers in treating non-surgical complications and diseases.

Methods: Authentic information from articles was extracted and evaluated to assess low-power laser performance for non-surgical treatments. A systematic search of studies on low-level laser therapy (LLLT) for non-surgical treatments was conducted mainly in PubMed and google scholar articles.

Results: Four categories of diseases, including brain-related diseases, skin-related diseases, cancers, and bone-related disorders, which were treated by LLLT were identified and introduced. The various types of LLLT regarding the studied diseases were discussed.

Conclusion: Positive aspects of LLLT versus a few disadvantages of its application imply more investigation to find better and efficient new methods.

Keywords: Low-level laser therapy; Photobiomodulation; Disorders; Treatment; Side effects.
\end{abstract}

\section{Introduction}

Laser treatment covers various fields in the clinic. Different types of lasers are used in this regard, including cold or low-level laser therapies (LLLT or class III laser) and high-power laser therapy (class IV).${ }^{1-4}$ LLLT is widely used in the clinic and encompasses a range of noninvasive therapeutic aspects. LLLT is commonly used clinically as a red light near-infrared wave with a length of 600 to $1000 \mathrm{~nm}$ and 5 to $500 \mathrm{~mW} .^{5}$ On the contrary, lasers used in surgery have a wavelength of $300 \mathrm{~nm} .{ }^{6}$ Low-power lasers are capable of penetrating deep into the skin so that the surface of the skin does not burn and damage. ${ }^{7}$ Lowpower or cold lasers have been enhanced to the point of being able to produce analgesia and healing acceleration for many clinical conditions. ${ }^{8} \mathrm{~A}$ wide range of LLLT and related techniques have been used. Therefore, the results of treatment with low-power lasers may contradict each other. ${ }^{9}$ LLLT may be administrated by many dermatologists, physical and occupational therapists, physicians and chiropractic doctors. ${ }^{10}$ The biostimulatory healing effect of LLLT may cause the treatment of chronic pain, commonly associated with carpal tunnel syndrome, arthritis, tissue injuries and severe wounds. ${ }^{11-15}$ On the other hand skin rejuvenation also may be another administration of lasers. ${ }^{16}$ There are many pieces of evidence about LLLT usage for the treatment of wound healing, ${ }^{17}$ tuberculosis, ${ }^{18}$ pain, tinnitus, ${ }^{19}$ epicondylitis, ${ }^{20}$ smoking cessation, ${ }^{21}$ Achilles tendinitis, ${ }^{22}$ back pain, ${ }^{23}$ plantar heel pain, ${ }^{24}$ Carpal tunnel syndrome, ${ }^{25}$ and the primary Raynaud's phenomenon. ${ }^{26}$ However, others published documents revealed inadequate efficiency of LLLP for wound healing, ${ }^{27}$ arthritis, ${ }^{28}$ tinnitus, ${ }^{29}$ tuberculosis, ${ }^{30}$ epicondylitis, ${ }^{31}$ and plantar heeling pain. ${ }^{32}$ Therefore, a comprehensive research study on the evaluation of laser function in therapeutic interventions seems necessary.

\section{Methods}

Articles that explain the effects of laser therapy on non-surgical disorders and complications in the online journals published from 1990 until 2019 were considered. An online search in google scholar and PubMed using the keywords "Non-surgical", "laser", "side effects" "treatment" "assessment", and "photobiomodulation" 
was performed. The titles and abstracts of 320 collected articles in the English language were studied and 253 appropriate articles were selected to be included in the study. Subsequently, the articles related to the inclusion criteria established previously were chosen. Finally, 164 documents were evaluated and considered as the related article. However, there are many related articles which have overlap with the studied documents.

\section{Results}

According to the finding, LLLT is applied to treat at least four categories of diseases including nervous system complications, skin and mucosal disorders, bone and joint disorders, and cancers. These four classes of diseases are tabulated in Table 1. We evaluated and studied the selected articles that have researched these categories of disorders.

\section{Nervous System Complications \\ Brain Photobiomodulation}

Researches in intracranial photobiomodulation have shown that the use of infrared or near-infrared light can promote cell repair. ${ }^{33}$ Near-infrared waves are capable of passing through the human skull and the cerebral cortex which could receive a small amount of energy. ${ }^{34}$ The abundant mitochondria present in neurons are the primary receptors for near-infrared and infrared wave energy. Subsequently, mechanisms such as increased ATP production, CMP activity and increased oxidative activation work together to prevent cell death during ischemic failure, brain injury, and neurodegeneration. ${ }^{35,36}$ This process can be mediated by increased expression of genes involved in the cell survival process, such as the production of antioxidant enzymes, heat shock proteins, and cell death-preventing proteins. ${ }^{37}$ Transcranial light therapy has been developed to increase neuron proliferation in the hippocampus following a stroke or ischemia. $^{38}$

\section{Trigeminal Nerve Neuralgia}

Trigeminal nerve neuralgia (TN) is the major cause of face and mouth pains. ${ }^{39}$ The pathogenesis of TN neuralgia is not well understood and high vascular pressure causes demyelination of nerves following pons entrance. ${ }^{40}$ LLLT could decrease acute neuralgia via mechanisms such as decreasing histamine, serotonin, and bradykinin and increasing acetylcholinesterase, aerobic metabolism, ATP, encephalin, and endorphins production. ${ }^{41,42}$ Lasers could significantly increase the pain threshold and stimulate the synthesis of endorphins. ${ }^{43}$ Limited studies have been designed to assess the effects of LLLT on TN analgesia treatment with controversial results.

\section{Traumatic Brain Injury}

Traumatic brain injury (TBI) - the other subject that is treated via LLLT - is one of the main causes of morbidity and mortality in young military staff or athletes along with accidents. ${ }^{44}$ Several cell and tissue interactions lead to inflammation and brain edema and cerebral perfusion. The combination of defects results in brain ischemia and diminishing oxygen and glucose transportation to the neurons. Membrane channel transportation changes together with voltage postsynaptic enhancement. ${ }^{45}$ Calcium rises inside the neurons with mitochondrial malfunction and apoptosis happens simultaneously in TBI. ${ }^{46}$

\section{Neuropathic Pain}

Primary lesions and dysfunctions of the nervous system may cause neuropathic pain. It seems that LLLT may cause the treatment of this kind of pain; however, there are controversies between different applications. LLLT is a suitable method for neuropathic pain treatment; different wavelengths of lasers which are reported in several studies revealed increased analgesia significantly. ${ }^{47-50}$ The importance of LLLT in the treatment of diabetic neuropathy was investigated due to the antioxidant and biomodulation effects of lasers as a non-pharmacological treatment. ${ }^{51,52}$ Another study carried out different mechanisms of LLLT in pain relief as inflammatory process modulation, excitation alteration, and endorphins secretion. ${ }^{53}$ Bradykinin reduction with the modulation of the inflammatory process according to the LLLT pain relief mechanism is reported through researches. ${ }^{54,55}$ The $\beta$-endorphin expression seems to be a secondary action of LLLT in analgesia. ${ }^{56}$ Red and infra-red laser effects on analgesia amplification have been reported with a controversy between two lasers. ${ }^{57,58}$ The density of LLLT energy seems to be an effective value in pain relief. However, there are some discrepancies between the results of the assessments. ${ }^{48,59}$

Table 1. Summary of Different Complications Treated by LLLT

\begin{tabular}{lccc}
\hline Nervous System Complications & Skin and Mucosal Disorders & Cancers & Bone and Joint Disorders \\
\hline Brain photobiomodulation & Skin burn & Breast cancer lymphoma & Bone disorders \\
Trigeminal nerve neuralgia & Hair loss & Head \& neck cancer & Carpal tunnel syndrome \\
Traumatic Brain Injury & Pemphigus vulgaris & \\
Neuropathic pain & Diabetic foot ulcers & \\
& Herpes labialis & \\
\hline
\end{tabular}




\section{Skin And Mucosal Disorders}

Skin Burns

Burn with the thermal origin which is a traumatic injury could affect human organs. ${ }^{60}$ LLLT is a useful method for treating burning injuries, especially skin burns; however, there are some controversies between application parameters of LLLT in the treatment of skin burns. There are many factors causing skin burns, such as chemical, physical and biological factors, which lead to pain, infection, and even death. ${ }^{61}$ The mechanism of wound healing in cutaneous burns is the interaction between the cascade release of cytokines and the extracellular matrix and involves these steps: spontaneous and interdependent inflammation, proliferation, and remodeling. ${ }^{62}$ Early stages of repair are proliferation and edema and may modulate complications such as the reduction of leukocytes and macrophages, fibroblasts, and angiogenesis simultaneously. ${ }^{63}$ Those complications may lead to scar and tissue adhesions. ${ }^{64}$ Recent studies have shown that LLLT can be effective in the treatment of skin burns as a low-price and non-invasive treatment. ${ }^{65}$ The mechanism of laser action on biological tissues is mainly related to stimulating cytochrome oxidase releasing, and it activates intracellular cascade reactions and increases the intracellular and molecular synthesis and subsequently increases the synthesis of RNA and DNA which, in turn, increases cell proliferation and migration in the injured tissue restoration. ${ }^{66-68}$ Lab experimental researches revealed that LLLT increases fibroblasts proliferation and collagen synthesis along with tissue granulation. These cellular events resulted in the acceleration of wound contraction and re-epithelization. ${ }^{69-71}$ The study on laser therapy for wound healing has been the subject of researches since its inception and its first report was published in $1971 .^{66}$ In the following years, many studies were performed in this area and the upward trend of laser burn and wound healing methods was studied too; however, differences in the methods, including the wavelength and energy used and the power of radiation and duration of treatment in different studies, were significant. ${ }^{72,73}$ The $600-700 \mathrm{~nm}$ wavelengths have less penetrating power than the 700$1000 \mathrm{~nm}$ wavelengths within the tissue. ${ }^{68}$ Researchers have used different wavelengths for LLLT. ${ }^{74,75}$ Some researchers have considered the $660 \mathrm{~nm}$ wavelength for the initial stages of skin wound healing and the $780 \mathrm{~nm}$ wavelength effective for the formation of tissue granulation. ${ }^{76}$

\section{Hair Loss}

Recent investigations have revealed that LLLT could evaluate hair growth stimulation. Studies on hair loss of male and female cases, chemotherapy-induced alopecia and alopecia aerate have demonstrated the effectiveness of LLLT in hair re-growth. The first study about hair growth was published by Ferrando et al in 2002. ${ }^{77}$ They used IPL photomodulation to remove unwanted hair but the results were paradoxically positive for hair growth.
However, studies on the LLLT treatment of alopecia are limited in numbers of documents and the wavelengths from 600 to $1000 \mathrm{~nm}$ were in preference. Leavitt et al assessed the effects of a laser with the wavelengths of 635 and $660 \mathrm{~nm}$ and a combination of both on the hair growth of the forearm. The results revealed the positive effects of LLLT on hair follicle growth compared to the control group. ${ }^{78}$ In another study, it was revealed that evaluated laser devices could increase hair growth elongation on day 3 of treatment compared to the control group. ${ }^{79}$ The very low incidence of LLLT side effects made it safe to use for hair growth. ${ }^{80}$ In animal experiments, results revealed the positive effects of LLLT on hair growth for alopecia aerate AA), ${ }^{81}$ and chemotherapy-induced alopecia. ${ }^{82}$ On the other hand, King et al did not have positive results for AA treatment by LLLT in mice, as opposed to the results of a study by Wikramanayake et al. ${ }^{83}$ Clinical trials revealed the positive effects of LLLT on hair re-growth. ${ }^{84-90}$

\section{Pemphigus Vulgaris}

Pemphigus vulgaris (PV) is a chronic blistering disease with antibodies directed against keratinocytes. ${ }^{91}$ Management of PV is difficult. Steroid therapy is still the basic treatment of disease with some adverse effects. ${ }^{92}$ Various laser devices have been used to treat PV. There are some reports about wounds that are related to $\mathrm{PV} .^{93}$ Based on previous investigations the mouth is affected by PV. Lesions of gingiva and mucosa of mouth and the other parts of body are reported in the PV patients. ${ }^{94,95}$ The assessment of LED laser therapy of PV with a $660 \mathrm{~nm}$ wavelength in a continuous wave and $30 \mathrm{~mW}$ energy in 10 patients revealed the efficiency of LLLT in the treatment of PV ulcers. ${ }^{96}$

\section{Diabetic Foot Ulcers}

One of the complications in diabetes mellitus is longlasting or non-healing skin ulcers of the foot and the results of treatments are not satisfactory for patients. ${ }^{97}$ LLLT as an effective and noninvasive tool could be seemingly manageable for a diabetic foot ulcer. $^{98}$ Multifactorial occurrences such as peripheral neuropathy and arterial occlusive disorders may cause foot diabetic syndrome. ${ }^{99}$ As it is shown in Table 2, diabetic ulcers (DUs) could be classified according to Wagner and Armstrong ulcer classifications. ${ }^{100}$

Conventional treatments as wound cleaning, skin grafting, vasodilators, and antibiotics could be still unsatisfactory. ${ }^{101}$ LLLT has been introduced as a painless and noninvasive treatment without major side effects for DU treatment. Low-power lasers with low-energy radiation stimulate cell activity, but high-power lasers have adverse effects on cell activity, and in non-healing DUs, the application of lasers to stimulate wound healing has been recommended. ${ }^{102}$ The laser needle is a new method of laser acupuncture which its therapeutic effects are similar to manual needle acupuncture. ${ }^{103} \mathrm{~A}$ unique 
Table 2. Wagner \& Armstrong Ulcer Classification in Summary

\begin{tabular}{lll}
\hline Wagner Grade & Lesion & Armstrong Ulcer Grades \\
\hline 0 & No open wounds & A: Without infection or ischemia \\
1 & Superficial wounds & B: With infection \\
2 & Ulcer extension & C: With Ischemia \\
3 & Deep ulcer & D: With infection and ischemia \\
4 & Localized Gangrene & \\
5 & Extensive Gangrene & \\
\hline
\end{tabular}

laser therapy mode determination to treat diabetic foot ulcers is not explained yet. Kajagar et al compared pulsed LLLT on 85 diabetic wound healing patients on the basis of wound size, duration of exposure and used energy in the surface of the wound $\left(2-4 \mathrm{~J} / \mathrm{cm}^{2}\right.$ at $60 \mathrm{~mW}$ for 15 days). There was a significant ulcer reduction in LLLT compared with traditional treatment methods. ${ }^{98}$ Another review of wound treatments focusing on venous leg ulcers and decubitus ulcers claimed LLLT could not improve wound healing and suggested that researches should focus on molecular and cellular mechanisms of wound healing with more investigation in humans to find precise laser parameters and treatment protocols. ${ }^{104}$

\section{Herpes Labialis}

This is a viral disease, which could not be treated completely and anti-viral drugs acyclovir, valacyclovir, and famciclovir could not eliminate the virus. ${ }^{105}$ Different kinds of laser therapy and several protocols have been proposed for the treatment of herpes labialis (HL) based on successful clinical trials recently. Different studies reported the wavelengths between 630 and $980 \mathrm{~nm}$ and power of 20 to $300 \mathrm{~mW}$ with radiation duration between 10 seconds and 15 minutes respectively for HL treatment. ${ }^{106}$ All the researchers reported that LLLT is an effective tool in the management of HL prevention without any side effects.

\section{Cancers}

\section{Breast Cancer Lymphedema}

Early diagnosis and treatment of breast cancer result in the survival of more than $82 \%$ patients in developed countries. ${ }^{107}$ However, more survived patients suffer from secondary lymphedema due to the following cancer therapies. ${ }^{108}$ Despite efforts to reduce breast cancer lymphedema (BCL) by treatments such as surgery or radiotherapy, BCL remained relevant. ${ }^{109}$ During the past few years, LLLT has been introduced as suitable noninvasive phototherapy for the treatment of BCL, with the wavelength between 650 and $1000 \mathrm{~nm}$ to be delivered into the target tissue to reduce inflammation and promote lymphatic vessel regeneration and lymphatic mortality reduction. ${ }^{110-112}$ LLLT was more effective than compression bandage for pain relief in BCL post-treatment ${ }^{113}$. Based on previous studies infrared radiation (808 to $905 \mathrm{~nm}$ ) is applied to LLLT of BCL post treatment (Table 3). The range of energy usage was $1.5 \mathrm{~J} / \mathrm{cm}^{2}$ to $2.4 \mathrm{~J} / \mathrm{cm}^{2}$. ${ }^{114}$.

\section{Head and Neck Cancer}

Several types of related complications of head and neck cancer (HNC), which are treated via LLLT, are tabulated in Table 3.

\section{Oral Mucositis}

Most of the patients with HNC treated by radiotherapy (RT) or chemotherapy (CT) suffered from orofacial and oropharyngeal complications. ${ }^{115}$ Most patients confront multiple complications, leading to a negative impact on their lifestyle. ${ }^{116}$ Supportive care for these complications should be considered in different stages of the disease. Photobiostimulation with various kinds of light energy as LLLT and LED and visible light has shown a promising efficiency for the treatment of HNC complications. ${ }^{117}$ Oral mucositis almost appears in all of the HNC patients treated by CT. ${ }^{118}$ Some investigations have claimed that photobiomodulation is efficient for oral mucositis, a complication that appears after HNC routine treatments. ${ }^{119,120}$ There are several complications resulted from HNC such as "Oral mucositis, ${ }^{121}$ dermatitis, ${ }^{122}$ dysphagia, ${ }^{123}$ hyposalivation and xerostornia, ${ }^{124}$ taste alterations, ${ }^{125}$ osteoradionecrosis, ${ }^{126}$ trismus, ${ }^{127}$ soft tissue necrosis, ${ }^{128}$ head and neck lymphedema, ${ }^{129}$ and voice alterations." ${ }^{130}$ All of those complications could be treated by photomodulation (see Table 3 ). Oral mucositis affects patients with HNC, treated by oral CT from mild to severe conditions. ${ }^{131}$ ROS production starting cascade reactions leads to microvascular injuries and ECM alterations in mucositis. ${ }^{132}$ Different meta-analysis assessments revealed

Table 3. Different Complications Resulted From Head and Neck Cancer Treated by Photobiomodulation

\begin{tabular}{|c|c|c|c|c|}
\hline Head \& Neck Cancer Complications & Photobiomodulation Therapy & Wavelengths & Power Supply & Efficiency \\
\hline Oral mucositis & IR \& NIR \& LLLT & $630-830 \mathrm{~nm}$ & $10-150 \mathrm{~mW}$ & Positive \\
\hline \multirow{2}{*}{ Dermatitis } & IR LED & $630-680 \mathrm{~nm}$ & 20-150 mW & Positive \\
\hline & Red \& IR LED & $630-680 \mathrm{~nm}$ & $20-80 \mathrm{~mW}$ & Positive \\
\hline Dysphagia & IR-NIR & 980nm & - & Positive \\
\hline Osteoradio necrosis & Red \& IR & $660-800 \mathrm{~nm}$ & $100 \mathrm{~mW}$ & Positive \\
\hline \multirow{2}{*}{ Trismus } & Diode Laser & $980 \mathrm{~nm}$ & $30 \mathrm{~mW}$ & Positive \\
\hline & Ga-Al-As & $830 \mathrm{~nm}$ & $30 \mathrm{~mW}$ & Negative \\
\hline \multirow{2}{*}{ Head \& neck lymphedema } & LLLT & $650-1000 \mathrm{~nm}$ & $20-80 \mathrm{~mW}$ & Positive \\
\hline & LLLT & $808-905 \mathrm{~nm}$ & $20-80 \mathrm{~mW}$ & Positive \\
\hline
\end{tabular}


the efficiency of photobiomodulation in mucositis reduction and pain-relieving with different doses of light energy consumption. ${ }^{133}$ IR (630-680 nm) and NIR (780$830 \mathrm{~nm}$ ) lights had the same efficiency for the treatment of mucositis. ${ }^{134}$

\section{Dermatitis}

HNC patients treated by RT mostly have dermatitis. Radiotherapy leads to the release of inflammatory cytokines as interleukin I \& VI and this process causes the development of edema, erythema and possibly ulceration. ${ }^{135}$ Radiation of the skin could damage basal epithelial cells and connective tissue vascular components. Photobiomodulation may reduce the severity of radiation dermatitis. ${ }^{68}$ Damage to the skin developed by radiation may be ameliorated by multi-wavelength photobiomodulation. ${ }^{136}$ In a review by Bensadon et al, the effects of the red laser diode cluster and the IR LED cluster on radiation dermatitis were evaluated positively due to reduction of pain and inflammation and also promotion of tissue repair after LLLT administration. However, more investigations were suggested to reduce the side effects of LLLT and the photobiomodulation treatment of dermatitis. ${ }^{137}$

\section{Dysphagia}

Dysphagia is an impairment of swallowing and could be seen in patients with head and neck malignancy as a side effect of cancer therapy. ${ }^{138}$ Dysphagia is associated with inflammation, edema, and fibrosis. ${ }^{139}$ Photobiomodulation is a promising technique for dysphagia treatment. ${ }^{140}$ Dysphagia has different stages from 0 to V. According to references, treatment could be intraoral and extraoral photobiomodulation. ${ }^{141}$ Using an IR laser with a wavelength of $980 \mathrm{~nm}$ (Table 3), Mobadder et al reported the effectiveness of LLLT in cancer resulted from a dysphagia case in pre- and post-operative stages. ${ }^{141}$

\section{Osteoradionecrosis}

Oral cancers may need different treatments such as surgery, radiotherapy, chemotherapy or a combination of these techniques. Chronic side effects of an oral cavity may cause bone repair capacity to diminish. ${ }^{142,143}$ Osteoradionecrosis (ORN) means a condition that the irradiated bone be exposed into the oral cavity more than 12 weeks and this process occurs in the suppression of tumor recurrence or tumor necrosis in RT. ${ }^{144}$ There is no cure for ORN and only clinical control treatments as surgical debris removing, antibiotic therapy, and ultrasound could be performed. ${ }^{144-146}$ LLLT with increasing metabolism capacity, cell proliferation, angiogenesis and wound healing is a suitable method for assisting ORN treatment. ${ }^{147}$ LLLT also has analgesic effects and improves lymphatic flow. ${ }^{148}$ Riberio et al in a study analyzed ORN treatment by LLLT. The objective of the study was the stimulation of the affected area to homeostasis, leading to oral mucosa healing. Red light and IR lasers (see Table 3) were used for bone exposure and the affected jaw subsequently. LLLT improved the healing process of bone and accelerated the covering of bone with oral mucosa in most cases. ${ }^{149}$ Positive results of LLLT as an adjuvant therapy suggested for ORN treatment.

\section{Trismus}

Lockjaw or trismus is a limited jaw range of motion. It may be caused by HNC. LLLT is an efficient tool to reduce pain, edema and inflammation without adverse effects to promote damaged tissue repairing. ${ }^{150}$ Petrini et al revealed the effect of LLLT treatment with the aid of an $890 \mathrm{~nm}$ (Table 3) diode laser on pain and edema reduction. ${ }^{151}$

\section{Bone and Joint Disorders \\ Bone Disorders}

Bone regeneration is accelerated by laser treatment in Wistar rats relative to the controls. ${ }^{152}$ Improvement of closed bone fracture healing in human wrist and hand via LLLT is reported by Chang et al. ${ }^{153}$

\section{Tendon Repair}

As it is reported, a low-level laser in combination with adipose-derived mesenchymal stem cells improves the initial phase of tendon repair. ${ }^{154}$ Based on the investigation by Badawy et al, laser therapy can be used to recover hand flexor tendon repair. ${ }^{155}$

\section{Carpal Tunnel Syndrome}

Tezcan et al investigated the effect of LLLT on 34 patients with carpal tunnel syndrome. On the basis of this report, the LLLT strain ratio and the cross-sectional area of the median nerve in patients decreased after LLLT. They concluded that nerve regeneration and development of the vascular supply effects of laser therapy led to the improvement of patients' condition. ${ }^{156}$

\section{Discussion}

As noted in the introduction, the types of complications which can be treated with low-power lasers include disorders of the nervous system, skin and mucous membranes of the body, bones and joints, and finally cancers. It should be noted that according to the reviewed articles, one of the common treatments for the above complications by low-power laser is pain relief. Given the variety of sources studied, the conclusion that the wavelengths and energy used in different lowpower lasers for the treatment of these diseases are different is a point that needs to be considered because there are no specific protocols to treat each of the above-introduced side effects by low-laser and much research is still needed in this regard. As it is presented in Table 1, four types of nervous system complications 
including Brain photobiomodulation, trigeminal nerve neuralgia, traumatic brain injury, and neuropathic pain are treated via LLLT. According to the studied sources, photobiomodulation modulates nerve cells, but in relation to trigeminal neuralgia, some articles reported positive effects of LLLT on TN treatment and others didn't have any significant difference between tested groups. The wavelength of light and the size of samples are the factors that need more investigations. ${ }^{39}$ TBI treated by LLLT leads to increasing the brain neurotrophic factor and synaptogenesis. ${ }^{157}$ LLLT may cause neuropathic pain treatment but there are some controversies. However, there is a lack of detail on laser and energy density parameters in the reviewed articles to assess the LLLT effect on analgesia. According to Arnold Shultz law, the biological responses in tissues could change (stimulate or inhibit) according to the dose of energy absorption ${ }^{158}$ and more investigation is necessary to define the protocols for optimizing LLLT in neuropathic pain relief as different doses of energy are provided by different instruments. In the field of skin and mucosal disorders, skin burns revealed that the size of the wound and classification of the lesion may explain total energy discrepancy in different studies; however, it could be concluded that LLLT could promote the wound healing process, but the gap in the current literature may cause the limitation of opening a window to suggest a suitable and precise method for the specifications of skin burn healing by LLLT. Hair loss treatment with LLLT also reminds us that the phenomenon named "paradoxical hypertrichosis" was the result of low influences of different types of lasers, being enough for hair growth but not enough to induce thermolysis with the range of $0.6 \%$ to $10 \% .{ }^{159}$ Suitable randomized controlled trials in a clinic are required to assess the efficiency of LLLT for hair growth. ${ }^{160}$ However, more studies are required to create optimal protocols for such parameters as wavelengths, flounce, pulse type, time and power density of LLLT evaluation for hair re-growth. ${ }^{80}$ Combined treatment of drugs and LLLT needs more clinical trials suggested by researchers. ${ }^{80}$ Diabetic foot ulcer treatment with LLLT is a subject of controversy. Unique laser therapy mode determination to treat diabetic foot ulcers is not explained yet. It could be generally concluded that the laser effects are generally different in certain ulcers, ${ }^{161}$ and animal studies revealed the promotion of wound healing by laser irradiation due to different factors such as cellular, morphological and collagen synthesis improvement. ${ }^{162,} 163$ However, further investigations and clinical trials are required to understand efficacy of LLLT on diabetic wound healing according to the available positive results of studies. HL has different treatments and dissimilar protocols which implies more precise clinical trials with standard laser parameters be considered. As mentioned in Table 3 for breast cancer, different wavelengths and power supplies to use in LLLT treatments should be considered. A need to identify the optimal parameters of photobiomodulation for oral mucositis and dermatitis treatment is still required because of the controversies in different laser parameters that have been used by researchers (see Table 3 ) and the reduction of treatment side effects is still a problem. ORN treatment by LLLT is suggested by clinicians because of the proliferation and angiogenesis characters of laser therapy in this regard. Trismus treatment by LLLT was suggested, but some studies have not confirmed the effect of lowpower lasers on muscle spasm reduction, which may be due to differences in sample type and other standards such as radiation intensity and the dose and depth of penetration. ${ }^{164}$ Further research is required to introduce standard LLLT therapy for trismus treatment. It can be concluded that LLLT is in the initial step to be applied in a clinic in spite of the considerable development of related methods and theories.

\section{Conclusion}

Based on the studies of the low-power laser in the treatment of non-surgical diseases, it can be concluded that most studies have shown its positive effects on the treatment of such diseases, but lack of consistency in the choice of laser standards such as the wavelength, the amount of energy consumed, the surface of laser contact, and the duration of treatment is seen. Most researchers believe that in relation to each of the diseases, the efficiency of the lowpower laser is positive. Standard research with qualitative and quantitative assumptions in the clinical setting should be undertaken to achieve original protocols to treat nonsurgical diseases with LLLT and photobiomodulation. It seems that LLLT is a useful therapeutic method with a high degree of capacity for progression in future.

\section{Ethical Considerations}

Not applicable.

\section{Conflict of Interests}

The authors declare no conflict of interest.

\section{Acknowledgment}

Shahid Beheshti University of Medical Sciences supported this research.

\section{References}

1. Khalkhal E, Razzaghi M, Rostami-Nejad M, RezaeiTavirani M, Heidari Beigvand H, Rezaei Tavirani M. Evaluation of laser effects on the human body after laser therapy. J Lasers Med Sci. 2020;11(1):91-7. doi: 10.15171/ jlms.2020.15.

2. Rezaei-Tavirani M, Tavirani MR, Zamanian Azodi M, Moravvej Farshi H, Razzaghi M. Evaluation of skin response after Erbium:yttrium-aluminum-garnet laser irradiation: a network analysis approach. J Lasers Med Sci. 2019;10(3):194-99. doi: 10.15171/jlms.2019.31.

3. Mansouri V, Rezaei-Tavirani M, Zadeh-Esmaeel MM, Rezaei-Tavirani S, Razzaghi M, Okhovatian F, et al. Analysis of laser therapy effects on squamous cell 
carcinoma patients: A system biology study. J Lasers Med Sci. 2019;10(Suppl 1):S1-S6. doi: 10.15171/jlms.2019.S1.

4. Safaei A, Rezaei Tavirani M, Zamanian Azodi M, Lashay A, Mohammadi SF, Broumand MG, et al. Diabetic retinopathy and laser therapy in rats: A protein-protein interaction network analysis. J Lasers Med Sci. 2017;8(Suppl 1):S20-S21. doi: 10.15171/jlms.2017.s4.

5. Seifi M, Shafeei HA, Daneshdoost S, Mir M. Effects of two types of low-level laser wave lengths (850 and $630 \mathrm{~nm}$ ) on the orthodontic tooth movements in rabbits. Lasers Med Sci. 2007;22(4):261-4. doi: 10.1007/s10103-007-0447-9.

6. Kabnick LS. Outcome of different endovenous laser wavelengths for great saphenous vein ablation. J Vasc Surg. 2006;43(1):88-93. doi: 10.1016/j.jvs.2005.09.033.

7. Esnouf A, Wright PA, Moore JC, Ahmed S. Depth of penetration of an $850 \mathrm{~nm}$ wavelength low level laser in human skin. Acupunct Electrother Res. 2007;32(1-2):81-6. doi: 10.3727/036012907815844165.

8. Ferreira DM, Zângaro RA, Villaverde AB, Cury Y, Frigo L, Picolo G, et al. Analgesic effect of He-Ne $(632.8 \mathrm{~nm})$ low-level laser therapy on acute inflammatory pain. Photomed Laser Surg. 2005;23(2):177-81. doi: 10.1089/ pho.2005.23.177.

9. Navratil L, Kymplova J. Contraindications in noninvasive laser therapy: truth and fiction. J Clin Laser Med Surg. 2002;20(6):341-3. doi: 10.1089/104454702320901134.

10. Kitchen SS, Partridge CJ. A review of low level laser therapy: Part I: background, physiological effects and hazards. Physiotherapy. 1991;77(3):161-8. doi: 10.1016/ S0031-9406(10)61694-X.

11. Walker J. Relief from chronic pain by low power laser irradiation. Neurosci Lett. 1983;43(2-3):339-44. doi: 10.1016/0304-3940(83)90211-2.

12. Shooshtari SMJ, Badiee V, Taghizadeh SH, Nematollahi AH, Amanollahi AH, Grami MT. The effects of low level laser in clinical outcome and neurophysiological results of carpal tunnel syndrome. Electromyogr Clin Neurophysiol. 2008;48(5):229-31.

13. Van Dinten LC, Wassenaar AL, Gorbalenya AE, Spaan WJ, Snijder EJ. Processing of the equine arteritis virus replicase ORF1b protein: identification of cleavage products containing the putative viral polymerase and helicase domains. J Virol. 1996;70(10):6625-33. doi: 10.1128/ jvi.70.10.6625-6633.1996.

14. Garavello-Freitas I, Baranauskas V, Joazeiro PP, Padovani CR, Dal Pai-Silva M, da Cruz-Höfling MA. Low-power laser irradiation improves histomorphometrical parameters and bone matrix organization during tibia wound healing in rats. J Photochem Photobiol B. 2003;70(2):81-9. doi: 10.1016/s1011-1344(03)00058-7.

15. Hawkins D, Houreld N, Abrahamse H. Low level laser therapy (LLLT) as an effective therapeutic modality for delayed wound healing. Ann N Y Acad Sci. 2005;1056(1):486-93. doi: 10.1196/annals.1352.040.

16. Lubart R, Friedmann H, Lavie R, Longo L, Jacobi J, Baruchin $\mathrm{O}$, et al. A reasonable mechanism for visible lightinduced skin rejuvenation. Lasers Med Sci. 2007;22(1):1-3. doi: 10.1007/s10103-006-0406-x.

17. Vaghardoost R, Momeni M, Kazemikhoo N, Mokmeli S, Dahmardehei M, Ansari F, et al. Effect of low-level laser therapy on the healing process of donor site in patients with grade 3 burn ulcer after skin graft surgery (a randomized clinical trial). Lasers Med Sci. 2018;33(3):603-7. doi: 10.1007/s10103-017-2430-4.

18. Bhagwanani NS, Bhatia CC, Sharma N, Hemvani N, Chitnis DS. Low level nitrogen laser therapy in pulmonary tuberculosis. Laser ther. 2015;24(3):209-14. doi: 10.5978/ islsm.15-OR-14.

19. Nakashima T, Ueda H, Misawa H, Suzuki T, Tominaga $\mathrm{M}$, Ito A, et al. Transmeatal low-power laser irradiation for tinnitus. Otol Neurotol. 2002;23(3):296-300. doi: 10.1097/00129492-200205000-00011.

20. Bjordal JM, Lopes-Martins RA, Joensen J, Couppe C, Ljunggren AE, Stergioulas A, et al. A systematic review with procedural assessments and meta-analysis of low level laser therapy in lateral elbow tendinopathy (tennis elbow). BMC Musculoskelet Disord. 2008;9(1):75. doi: 10.1186/1471-2474-9-75.

21. Kerr CM, Lowe PB, Spielholz NI. Low level laser for the stimulation of acupoints for smoking cessation: a double blind, placebo controlled randomised trial and semi structured interviews. Journal of Chinese Medicine. 2008;86:46

22. Tumilty S, McDonough S, Hurley DA, Baxter GD. Clinical effectiveness of low-level laser therapy as an adjunct to eccentric exercise for the treatment of Achilles' tendinopathy: a randomized controlled trial. Arch Phys Med Rehabil. 2012;93(5):733-9. doi: 10.1016/j. apmr.2011.08.049.

23. Gur A, Karakoc M, Cevik R, Nas K, Sarac AJ, Karakoc M. Efficacy of low power laser therapy and exercise on pain and functions in chronic low back pain. Lasers Surg Med. 2003;32(3):233-8. doi: 10.1002/lsm.10134.

24. Ordahan B, Karahan AY, Kaydok E. The effect of highintensity versus low-level laser therapy in the management of plantar fasciitis: a randomized clinical trial. Lasers Med Sci. 2018;33(6):1363-9. doi: 10.1007/s10103-018-2497-6.

25. Dincer U, Cakar E, Kiralp MZ, Kilac H, Dursun H. The effectiveness of conservative treatments of carpal tunnel syndrome: splinting, ultrasound, and low-level laser therapies. Photomed Laser Surg. 2009;27(1):119-25. doi: 10.1089/pho.2008.2211.

26. Hirschl M, Katzenschlager R, Francesconi C, Kundi M. Low level laser therapy in primary Raynaud's phenomenon-results of a placebo controlled, double blind intervention study. J Rheumatol. 2004;31(12):2408-12.

27. Cullum N, Nelson EA, Flemming K, Sheldon T. Systematic reviews of wound care management: (5) beds; (6) compression; (7) laser therapy, therapeutic ultrasound, electrotherapy and electromagnetic therapy. Health Technol Assess. 2001;5(9):1-221. doi: 10.3310/hta5090.

28. Meireles SM, Jones A, Jennings F, Suda AL, Parizotto NA, Natour J. Assessment of the effectiveness of low-level laser therapy on the hands of patients with rheumatoid arthritis: a randomized double-blind controlled trial. Clin Rheumatol. 2010;29(5):501-9. doi: 10.1007/s10067-009$1347-0$.

29. Tauber S, Schorn K, Beyer W, Baumgartner R. Transmeatal cochlear laser (TCL) treatment of cochlear dysfunction: a feasibility study for chronic tinnitus. Lasers Med Sci. 2003;18(3):154-61. doi: 10.1007/s10103-003-0274-6.

30. Vlassov VV, Pechatnikov LM, MacLehose HG. Low level laser therapy for treating tuberculosis. Cochrane Database of Syst Rev. 2002(3). 
31. Coates VH, Turkelson CM, Chapell R, Bruening W, Mitchell MD, Reston JT, et al. Diagnosis and treatment of worker-related musculoskeletal disorders of the upper extremity. Evid Rep Technol Assess (Summ). 2002(62):1-12.

32. Salvioli S, Guidi M, Marcotulli G. The effectiveness of conservative, non-pharmacological treatment, of plantar heel pain: A systematic review with meta-analysis. Foot (Edinb). 2017;33:57-67. doi: 10.1016/j.foot.2017.05.004.

33. Salehpour F, Mahmoudi J, Kamari F, Sadigh-Eteghad S, Rasta SH, Hamblin MR. Brain photobiomodulation therapy: a narrative review. Mol Neurobiol. 2018;55(8):660136. doi: 10.1007/s12035-017-0852-4.

34. Wan S, Parrish JA, Anderson RR, Madden M. Transmittance of nonionizing radiation in human tissues. Photochem Photobiol. 1981;34(6):679-81. doi: 10.1111/ j.1751-1097.1981.tb09063.x

35. Eells JT, Henry MM, Summerfelt P, Wong-Riley MTT, Buchmann EV, Kane $M$, et al. Therapeutic photobiomodulation for methanol-induced retinal toxicity. Proc Natl Acad Sci U S A. 2003;100(6):3439-44. doi: 10.1073/pnas.0534746100.

36. Wong-Riley MTT, Liang HL, Eells JT, Chance B, Henry MM, Buchmann E, et al. Photobiomodulation directly benefits primary neurons functionally inactivated by toxins: role of cytochrome c oxidase. J Biol Chem. 2005;280(6):4761-71. doi: 10.1074/jbc.M409650200.

37. Naeser MA, Hamblin MR. Potential for transcranial laser or LED therapy to treat stroke, traumatic brain injury, and neurodegenerative disease. Photomed Laser Surg. 2011;29(7):443-6. doi: 10.1089/pho.2011.9908.

38. Lapchak PA. Taking a light approach to treating acute ischemic stroke patients: transcranial near-infrared laser therapy translational science. Ann Med. 2010;42(8):576-86. doi: 10.3109/07853890.2010.532811.

39. Ebrahimi H, Najafi S, Khayamzadeh M, Zahedi A, Mahdavi A. Therapeutic and analgesic efficacy of laser in conjunction with pharmaceutical therapy for trigeminal neuralgia. J lasers Med Sci. 2018;9(1):63-8. doi: 10.15171/ jlms.2018.13.

40. de Leeuw R. Orofacial Pain: Guidelines for Assessment, Diagnosis and Management. $4^{\text {th }}$ ed. Chicago: Quintessence Publishing; 2008.

41. Ohno T. Pain suppressive effect of low power laser irradiation. A quantitative analysis of substance $\mathrm{P}$ in the rat spinal dorsal root ganglion. Nihon Ika Daigaku Zasshi. 1997;64(5):395-400. [In Japanese]. doi: 10.1272/ jnms1923.64.395.

42. Brondon P, Stadler I, Lanzafame RJ. Melanin density affects photobiomodulation outcomes in cell culture. Photomed Laser Surg. 2007;25(3):144-9. doi: 10.1089/pho.2007.2045.

43. Asnaashari M, Safavi N. Application of low level lasers in dentistry (endodontic). J Lasers Med Sci. 2013;4(2):57-66.

44. Taylor CA, Greenspan AI, Xu L, Kresnow MJ. Comparability of national estimates for traumatic brain injury-related medical encounters. J Head Trauma Rehabil. 2015;30(3):150-9. doi: 10.1097/HTR.0000000000000105.

45. Ross ST, Soltesz I. Selective depolarization of interneurons in the early posttraumatic dentate gyrus: involvement of the $\mathrm{Na}^{+} / \mathrm{K}^{+}$-ATPase. J Neurophysiol. 2000;83(5):2916-30. doi: 10.1152/jn.2000.83.5.2916.

46. Bramlett HM, Dietrich WD. Pathophysiology of cerebral ischemia and brain trauma: similarities and differences. J Cereb Blood Flow Metab. 2004;24(2):133-50. doi:
10.1097/01.WCB.0000111614.19196.04.

47. Zinman LH, Ngo M, Ng ET, Nwe KT, Gogov S, Bril V. Lowintensity laser therapy for painful symptoms of diabetic sensorimotor polyneuropathy: a controlled trial. Diabetes Care. 2004;27(4):921-4. doi: 10.2337/diacare.27.4.921.

48. Gustafsson H, Flood K, Berge OG, Brodin E, Olgart L, Stiller CO. Gabapentin reverses mechanical allodynia induced by sciatic nerve ischemia and formalin-induced nociception in mice. Exp Neurol. 2003;182(2):427-34. doi: 10.1016/s0014-4886(03)00097-9.

49. Ali-Asgarzadeh A, Agha-Mohammadi D, Movasaghi R, Shahsavari P. Effect of low-intensity laser on lower limb neuropathic pain in patients with diabetes mellitus. Journal of Anesthesiology and Pain. 2011;1(4):48-60. [In Persian].

50. Bertolini GRF, Artifon EL, da Silva TS, Cunha DM, Vigo PR. Low-level laser therapy, at $830 \mathrm{~nm}$, for pain reduction in experimental model of rats with sciatica. Arq Neuropsiquiatr. 2011;69(2B):356-9. doi: 10.1590/s0004$282 \times 2011000300017$.

51. Kalinina OV, Alekseeva NV, Burtsev EM. Infrared laser therapy in distal diabetic polyneuropathy. Zh Nevrol psikhiatr Im S S Korsakova. 1998;98(6):23-5. [In Russian]

52. Alcântara CC, Gigo-Benato D, Salvini TF, Oliveira AL, Anders JJ, Russo TL. Effect of low-level laser therapy (LLLT) on acute neural recovery and inflammation-related gene expression after crush injury in rat sciatic nerve. Lasers Surg Med. 2013;45(4):246-52. doi: 10.1002/lsm.22129.

53. Bjordal JM, Johnson MI, Iversen V, Aimbire F, LopesMartins RAB. Low-level laser therapy in acute pain: a systematic review of possible mechanisms of action and clinical effects in randomized placebo-controlled trials. Photomed Laser Surg. 2006;24(2):158-68. doi: 10.1089/ pho.2006.24.158.

54. Jimbo K, Noda K, Suzuki K, Yoda K. Suppressive effects of low-power laser irradiation on bradykinin evoked action potentials in cultured murine dorsal root ganglion cells. Neurosci Lett. 1998;240(2):93-6.

55. Chow R, Armati P, Laakso EL, Bjordal JM, Baxter GD. Inhibitory effects of laser irradiation on peripheral mammalian nerves and relevance to analgesic effects: a systematic review. Photomed Laser Surg. 2011;29(6):36581. doi: 10.1089/pho.2010.2928.

56. Hagiwara S, Iwasaka H, Hasegawa A, Noguchi T. Preirradiation of blood by gallium aluminum arsenide (830 $\mathrm{nm}$ ) low-level laser enhances peripheral endogenous opioid analgesia in rats. Anesth Analg. 2008;107(3):105863. doi: 10.1213/ane.0b013e31817ee43e.

57. Yan W, Chow R, Armati PJ. Inhibitory effects of visible 650-nm and infrared 808-nm laser irradiation on somatosensory and compound muscle action potentials in rat sciatic nerve: implications for laser-induced analgesia. $J$ Peripher Nerv Syst. 2011;16(2):130-5. doi: 10.1111/j.15298027.2011.00337.x.

58. Masoumipoor M, Jameie S, Janzadeh A, Nasirinezhad F, Soleimani M, Kerdary M. Effects of 660-and 980-nm lowlevel laser therapy on neuropathic pain relief following chronic constriction injury in rat sciatic nerve. Lasers Med Sci. 2014;29(5):1593-8. doi: 10.1007/s10103-014-1552-1.

59. Cidral-Filho FJ, Martins DF, Moré AOO, Mazzardo-Martins L, Silva MD, Cargnin-Ferreira E, et al. Light-emitting diode therapy induces analgesia and decreases spinal cord and sciatic nerve tumour necrosis factor-a levels after sciatic nerve crush in mice. Eur J Pain. 2013;17(8):1193-204. doi: 
10.1002/j.1532-2149.2012.00280.x.

60. Catarino HR, de Godoy NP, Scharlack NK, Neves LM, de Gaspi FO, Esquisatto MA, et al. InGaP 670-nm laser therapy combined with a hydroalcoholic extract of Solidago chilensis Meyen in burn injuries. Lasers Med Sci. 2015;30(3):1069-79. doi: 10.1007/s10103-014-1707-0.

61. Ezzati A, Bayat M, Taheri S, Mohsenifar Z. Low-level laser therapy with pulsed infrared laser accelerates thirddegree burn healing process in rats. J Rehabil Res Dev. 2009;46(4):543-54. doi: 10.1682/jrrd.2008.09.0121.

62. Brassolatti P, Bossini PS, Oliveira MCD, Kido HW, Tim CR, Almeida-Lopes L, et al. Comparative effects of two different doses of low-level laser therapy on wound healing thirddegree burns in rats. Microsc Res Tech. 2016;79(4):313-20. doi: $10.1002 /$ jemt.22632.

63. Chiarotto GB, Neves LMG, Esquisatto MAM, do Amaral MEC, dos Santos GMT, Mendonça FAS. Effects of laser irradiation (670-nm InGaP and 830-nm GaAlAs) on burn of second-degree in rats. Lasers Med Sci. 2014;29(5):168593. doi: 10.1007/s10103-014-1573-9.

64. Fu L, Zhang Y, Li C, Wu Z, Zhuo Q, Huang X, et al. Skin tissue repair materials from bacterial cellulose by a multilayer fermentation method. J Mater Chem. 2012;22(24):1234957. doi: $10.1039 / \mathrm{c} 2 \mathrm{jm} 00134 \mathrm{a}$.

65. Fiório FB, Albertini R, Leal-Junior ECP, de Carvalho Pde T. Effect of low-level laser therapy on types I and III collagen and inflammatory cells in rats with induced third-degree burns. Lasers Med Sci. 2014;29(1):313-9. doi: 10.1007/ s10103-013-1341-2.

66. de Vasconcelos Catão MHC, Nonaka CFW, de Albuquerque RLC, Bento PM, de Oliveira Costa R. Effects of red laser, infrared, photodynamic therapy, and green LED on the healing process of third-degree burns: clinical and histological study in rats. Lasers Med Sci. 2015;30(1):421-8. doi: 10.1007/s10103-014-1687-0.

67. Bayat M, Vasheghani MM, Razavi N, Taheri S, Rakhshan M. Effect of low-level laser therapy on the healing of seconddegree burns in rats: a histological and microbiological study. J Photochem Photobiol B. 2005;78(2):171-7. doi: 10.1016/j.jphotobiol.2004.08.012.

68. Avci P, Gupta A, Sadasivam M, Vecchio D, Pam Z, Pam $\mathrm{N}$, et al. Low-level laser (light) therapy (LLLT) in skin: stimulating, healing, restoring. Semin Cutan Med Surg. 2013;32(1):41-52.

69. Ezzati A, Bayat M, Khoshvaghti A. Low-level laser therapy with a pulsed infrared laser accelerates second-degree burn healing in rat: a clinical and microbiologic study. Photomed Laser Surg. 2010;28(5):603-11. doi: 10.1089/pho.2009.2544.

70. Karu TI, Pyatibrat LV, Afanasyeva NI. Cellular effects of low power laser therapy can be mediated by nitric oxide. Lasers Surg Med. 2005;36(4):307-14. doi: 10.1002/lsm.20148.

71. Ranjbar R, Ashrafzadeh Takhtfooladi M. The effects of low level laser therapy on Staphylococcus aureus infected thirddegree burns in diabetic rats. Acta Cir Bras. 2016;31(4):2505. doi: 10.1590/S0102-865020160040000005.

72. Núñez SC, França CM, Silva DFT, Nogueira GEC, Prates RA, Ribeiro MS. The influence of red laser irradiation timeline on burn healing in rats. Lasers Med Sci. 2013;28(2):633-41. doi: 10.1007/s10103-012-1105-4.

73. Karu T, Pyatibrat L, Kalendo G. Irradiation with HeNe laser increases ATP level in cells cultivated in vitro. J Photochem Photobiol B. 1995;27(3):219-23. doi: 10.1016/1011-1344(94)07078-3.
74. Renno ACM, Iwama AM, Shima P, Fernandes KR Carvalho JG, De Oliveira P, et al. Effect of low-level laser therapy $(660 \mathrm{~nm})$ on the healing of second-degree skin burns in rats. J Cosmet Laser Ther. 2011;13(5):237-42. doi: 10.3109/14764172.2011.606466.

75. Gupta A, Keshri GK, Yadav A, Gola S, Chauhan S, Salhan AK, et al. Superpulsed (Ga-As, $904 \mathrm{~nm}$ ) low-level laser therapy (LLLT) attenuates inflammatory response and enhances healing of burn wounds. J Biophotonics. 2015;8(6):489-501. doi: 10.1002/jbio.201400058.

76. Meireles GC, Santos JN, Chagas PO, Moura AP, Pinheiro AL. Effectiveness of laser photobiomodulation at 660 or 780 nanometers on the repair of third-degree burns in diabetic rats. Photomed Laser Surg. 2008;26(1):47-54. doi: 10.1089/pho.2007.2051.

77. Moreno-Arias G, Castelo-Branco C, Ferrando J. Paradoxical effect after IPL photoepilation. Dermatol Surg. 2002; 28(11):1013-6. doi: 10.1046/j.1524-4725.2002.02101.x.

78. Leavitt M. Evaluation of the activity of laser light doses compared to an inactive control dose on ex vivo hair growth. J Am Acad Dermatol. 2010;62(3): P2109.

79. Hamblin M. Evaluation of activity of laser doses on ex-vivo hair growth. http://www.hairmax.com/downloads/PDF/ EX_VIVO_STUDY_SLIDES_7_09.pdf. Accessed October 19, 2014.

80. Zarei M, Wikramanayake TC, Falto-Aizpurua L, Schachner LA, Jimenez JJ. Low level laser therapy and hair regrowth: an evidence-based review. Lasers Med Sci. 2016;31(2):36371. doi: 10.1007/s10103-015-1818-2.

81. Wikramanayake TC, Rodriguez R, Choudhary S, Mauro LM, Nouri K, Schachner LA, et al. Effects of the Lexington LaserComb on hair regrowth in the $\mathrm{C} 3 \mathrm{H} / \mathrm{HeJ}$ mouse model of alopecia areata. Lasers Med Sci. 2012;27(2):431-6. doi: 10.1007/s10103-011-0953-7.

82. Wikramanayake TC, Villasante AC, Mauro LM, Nouri K, Schachner LA, Perez CI, et al. Low-level laser treatment accelerated hair regrowth in a rat model of chemotherapyinduced alopecia (CIA). Lasers Med Sci. 2013;28(3):701-6. doi: 10.1007/s10103-012-1139-7.

83. King Jr LE, Silva KA, Kennedy VE, Sundberg JP. Lack of response to laser comb in spontaneous and graft-induced alopecia areata in $\mathrm{C} 3 \mathrm{H} / \mathrm{HeJ}$ mice. J Invest Dermatol. 2014;134(1):264-66. doi: 10.1038/jid.2013.252.

84. Satino JL, Markou M. Hair regrowth and increased hair tensile strength using the HairMax LaserComb for lowlevel laser therapy. Int J Cosmet Surg Aesthetic Dermatol. 2003;5(2):113-7. doi: 10.1089/153082003769591209.

85. Leavitt M, Charles G, Heyman E, Michaels D. HairMax LaserComb laser phototherapy device in the treatment of male androgenetic alopecia: A randomized, doubleblind, sham device-controlled, multicentre trial. Clin Drug Investig. 2009;29(5):283-92. doi: 10.2165/00044011200929050-00001.

86. Kim H, Choi JW, Kim JY, Shin JW, Lee Sj, Huh CH. Lowlevel light therapy for androgenetic alopecia: A 24-week, randomized, double-blind, sham device-controlled multicenter trial. Dermatol Surg. 2013;39(8):1177-83. doi: 10.1111/dsu. 12200 .

87. Lanzafame RJ, Blanche RR, Bodian AB, Chiacchierini RP, Fernandez-Obregon A, Kazmirek ER. The growth of human scalp hair mediated by visible red light laser and LED sources in males. Lasers Surg Med. 2013;45(8):487-95. doi: 10.1002/lsm.22173. 
88. Lanzafame RJ, Blanche RR, Chiacchierini RP, Kazmirek ER, Sklar JA. The growth of human scalp hair in females using visible red light laser and LED sources. Lasers Surg Med. 2014;46(8):601-7. doi: 10.1002/lsm.22277.

89. Jimenez JJ, Wikramanayake TC, Bergfeld W, Hordinsky M, Hickman JG, Hamblin MR, et al. Efficacy and safety of a low-level laser device in the treatment of male and female pattern hair loss: a multicenter, randomized, sham device-controlled, double-blind study. Am J Clin Dermatol. 2014;15(2):115-27. doi: 10.1007/s40257-013-0060-6.

90. Munck A, Gavazzoni MF, Trüeb RM. Use of low-level laser therapy as monotherapy or concomitant therapy for male and female androgenetic alopecia. Int J Trichology. 2014;6(2):45-49. doi: 10.4103/0974-7753.138584.

91. Nguyen VT, Ndoye A, Grando SA. Pemphigus vulgaris antibody identifies pemphaxin a novel keratinocyte annexin-like molecule binding acetylcholine. J Biol Chem. 2000;275(38):29466-76. doi: 10.1074/jbc.M003174200.

92. Scully C, Challacombe SJ. Pemphigus vulgaris: update on etiopathogenesis, oral manifestations, and management. Crit Rev Oral Biol Med. 2002;13(5):397-408. doi: 10.1177/154411130201300504.

93. Minicucci EM, Miot HA, Barraviera SRCS, Almeida-Lopes L. Low-level laser therapy on the treatment of oral and cutaneous pemphigus vulgaris: case report. Lasers Med Sci. 2012;27(5):1103-6. doi: 10.1007/s10103-012-1101-8.

94. Scully C, De Almeida OP, Porter SR, Gilkes JJ. Pemphigus vulgaris: the manifestations and long-term management of 55 patients with oral lesions. Br J Dermatol. 1999;140(1):849. doi: 10.1046/j.1365-2133.1999.02612.x.

95. Davenport S, Chen SY, Miller AS. Pemphigus vulgaris: clinicopathologic review of 33 cases in the oral cavity. Int $J$ Periodontics Restorative Dent. 2001;21(1):85-90.

96. Yousef M, Mansouri P, Partovikia M, Esmaili M, Younespour S, Hassani L. The effect of low level laser therapy on Pemphigus vulgaris lesions: A Pilot Study. J Lasers Med Sci. 2017;8(4):177-80. doi: 10.15171/jlms.2017.32.

97. Jeffcoate WJ, Harding KG. Diabetic foot ulcers. Lancet. 2003;361(9368):1545-51. doi: 10.1016/S01406736(03)13169-8.

98. Kajagar BM, Godhi AS, Pandit A, Khatri S. Efficacy of low level laser therapy on wound healing in patients with chronic diabetic foot ulcers-a randomised control trial. Indian J Surg. 2012;74(5):359-63. doi: 10.1007/s12262-0110393-4.

99. Beckmann KH, Meyer-Hamme G, Schröder S. Low level laser therapy for the treatment of diabetic foot ulcers: a critical survey. Evid Based Complement Alternat Med. 2014;2014:626127. doi: 10.1155/2014/626127.

100. Lipsky BA, Berendt AR, Cornia PB, Pile JC, Peters EJ, Armstrong DG, et al. 2012 Infectious Diseases Society of America clinical practice guideline for the diagnosis and treatment of diabetic foot infections. Clin Infect Dis. 2012;54(12):e132-e73.

101. Rüttermann M, Maier-Hasselmann A, Nink-Grebe B, Burckhardt M. Local treatment of chronic wounds: in patients with peripheral vascular disease, chronic venous insufficiency, and diabetes. Dtsch Arztebl Int. 2013;110(3):25-31. doi: 10.3238/arztebl.2013.0025.

102. Litscher G. Integrative laser medicine and hightech acupuncture at the Medical University of Graz, Austria, Europe. Evid Based Complement Alternat Med. 2012;2012:103109. doi: 10.1155/2012/103109.
103. Ebrahimi T, Moslemi N, Rokn A, Heidari M, Nokhbatolfoghahaie H, Fekrazad R. The influence of lowintensity laser therapy on bone healing. J Dent (Tehran). 2012;9(4):238-48.

104. Sobanko JF, Alster TS. Efficacy of low-level laser therapy for chronic cutaneous ulceration in humans: A review and discussion. Dermatol Surg. 2008;34(8):991-1000. doi: 10.1111/j.1524-4725.2008.34197.x.

105. de Paula Eduardo C, Aranha ACC, Simões A, BelloSilva MS, Ramalho KM, Esteves-Oliveira M, et al. Laser treatment of recurrent herpes labialis: a literature review. Lasers Med Sci. 2014;29(4):1517-29. doi: 10.1007/s10103013-1311-8.

106. Al-Maweri SA, Kalakonda B, AlAizari NA, Al-Soneidar WA, Ashraf S, Abdulrab S, et al. Efficacy of low-level laser therapy in management of recurrent herpes labialis: a systematic review. Lasers Med Sci. 2018;33(7):1423-30. doi: 10.1007/s10103-018-2542-5.

107. Pinto AC, De Azambuja E. Improving quality of life after breast cancer: dealing with symptoms. Maturitas. 2011;70(4):343-8. doi: 10.1016/j.maturitas.2011.09.008.

108. Cormier JN, Askew RL, Mungovan KS, Xing Y, Ross MI, Armer JM. Lymphedema beyond breast cancer: A systematic review and meta-analysis of cancer-related secondary lymphedema. Cancer. 2010;116(22):5138-49. doi: $10.1002 / \mathrm{cncr} .25458$.

109. Fu MR. Breast cancer-related lymphedema: Symptoms, diagnosis, risk reduction, and management. World J Clin Oncol. 2014;5(3):241-7. doi: 10.5306/wjco.v5.i3.241.

110. Nouri K, Jimenez GP, Harrison-Balestra C, Elgart GW. $585-\mathrm{nm}$ pulsed dye laser in the treatment of surgical scars starting on the suture removal day. Dermatol Surg. 2003;29(1):65-73. doi: 10.1046/j.1524-4725.2003.29014.x.

111. Assis L, Moretti AIS, Abrahão TB, de Souza HP, Hamblin MR, Parizotto NA. Low-level laser therapy (808 nm) contributes to muscle regeneration and prevents fibrosis in rat tibialis anterior muscle after cryolesion. Lasers Med Sci. 2013;28(3):947-55. doi: 10.1007/s10103-012-1183-3.

112. Jang DH, Song DH, Chang EJ, Jeon JY. Anti-inflammatory and lymphangiogenetic effects of low-level laser therapy on lymphedema in an experimental mouse tail model. Lasers Med Sci. 2016;31(2):289-96. doi: 10.1007/s10103-0151854-y.

113. Maiya AG, Olivia E, Dibya A. Effect of low energy laser therapy in the management of post-mastectomy lymphoedema. Physiotherapy Singapore. 2008;11(1):2-5.

114. Tumilty S, Munn J, McDonough S, Hurley DA, Basford JR, Baxter GD. Low level laser treatment of tendinopathy: a systematic review with meta-analysis. Photomed Laser Surg. 2010;28(1):3-16. doi: 10.1089/pho.2008.2470.

115. Epstein JB, Thariat J, Bensadoun RJ, Barasch A, Murphy BA, Kolnick L, et al. Oral complications of cancer and cancer therapy: from cancer treatment to survivorship. $C A$ Cancer J Clin. 2012;62(6):400-22. doi: 10.3322/caac.21157.

116. Hunter KU, Schipper M, Feng FY, Lyden T, Haxer M, Murdoch-Kinch CA, et al. Toxicities affecting quality of life after chemo-IMRT of oropharyngeal cancer: prospective study of patient-reported, observer-rated, and objective outcomes. Int J Radiat Oncol Biol Phys. 2013;85(4):935-40. doi: 10.1016/j.ijrobp.2012.08.030.

117. Zecha JA, Raber-Durlacher JE, Nair RG, Epstein JB, Elad S, Hamblin MR, et al. Low-level laser therapy/ photobiomodulation in the management of side effects of 
chemoradiation therapy in head and neck cancer: part 2: proposed applications and treatment protocols. Support Care Cancer. 2016;24(6):2793-805. doi: 10.1007/s00520016-3153-y.

118. Elting LS, Keefe DM, Sonis ST, Garden AS, Spijkervet F, Barasch A, et al. Patient-reported measurements of oral mucositis in head and neck cancer patients treated with radiotherapy with or without chemotherapy: demonstration of increased frequency, severity, resistance to palliation, and impact on quality of life. Cancer. 2008;113(10):270413. doi: $10.1002 / \mathrm{cncr} .23898$.

119. Clarkson JE, Worthington HV, Furness S, McCabe M, Khalid T, Meyer S. Interventions for treating oral mucositis for patients with cancer receiving treatment. Cochrane Database Syst Rev. 2010(8):CD001973.

120. Riley P, Glenny AM, Worthington HV, Littlewood A, Clarkson JE, McCabe MG. Interventions for preventing oral mucositis in patients with cancer receiving treatment: oral cryotherapy. Cochrane Database of Syst Rev. 2015(12):CD011552. doi: 10.1002/14651858.CD011552. pub2.

121. Bayer S, Kazancioglu HO, Acar AH, Demirtas N, Kandas NO. Comparison of laser and ozone treatments on oral mucositis in an experimental model. Lasers Med Sci. 2017;32(3):673-7. doi: 10.1007/s10103-017-2166-1.

122. Burdelya LG, Gleiberman AS, Toshkov I, Aygun-Sunar S, Bapardekar M, Manderscheid-Kern P, et al. Toll-like receptor 5 agonist protects mice from dermatitis and oral mucositis caused by local radiation: implications for headand-neck cancer radiotherapy. Int J Radiat Oncol Biol Phys. 2012;83(1):228-34. doi: 10.1016/j.ijrobp.2011.05.055.

123. Chen AY, Frankowski R, Bishop-Leone J, Hebert T, Leyk S, Lewin J, et al. The development and validation of a dysphagia-specific quality-of-life questionnaire for patients with head and neck cancer: the MD Anderson dysphagia inventory. Arch Otolaryngol Head Neck Surg. 2001;127(7):870-6.

124. Dirix P, Nuyts S, Van den Bogaert W. Radiation-induced xerostomia in patients with head and neck cancer: a literature review. Cancer. 2006;107(11):2525-34.

125. Halyard MY, Jatoi A, Sloan JA, Bearden III JD, Vora SA, Atherton PJ, et al. Does zinc sulfate prevent therapyinduced taste alterations in head and neck cancer patients? Results of phase III double-blind, placebo-controlled trial from the North Central Cancer Treatment Group (N01C4). Int J Radiat Oncol Biol Phys. 2007;67(5):1318-22. doi: 10.1016/j.ijrobp.2006.10.046.

126. Ben-David MA, Diamante M, Radawski JD, Vineberg KA, Stroup C, Murdoch-Kinch C-A, et al. Lack of osteoradionecrosis of the mandible after intensitymodulated radiotherapy for head and neck cancer: likely contributions of both dental care and improved dose distributions. Int J Radiat Oncol Biol Phys. 2007;68(2):396402. doi: 10.1016/j.ijrobp.2006.11.059.

127. Bensadoun RJ, Riesenbeck D, Lockhart PB, Elting LS, Spijkervet FK, Brennan MT. A systematic review of trismus induced by cancer therapies in head and neck cancer patients. Support Care Cancer. 2010;18(8):1033-8. doi: 10.1007/s00520-010-0847-4.

128. Hee LY, Kim YS, Chung MJ, Yu M, Jung SL, Yoo IR, et al. Soft tissue necrosis in head and neck cancer patients after transoral robotic surgery or wide excision with primary closure followed by radiation therapy. Medicine (Baltimore). 2016;95(9):e2852. doi: 10.1097/MD.0000000000002852.

129. Deng J, Ridner SH, Dietrich MS, Wells N, Wallston KA, Sinard RJ, et al. Prevalence of secondary lymphedema in patients with head and neck cancer. $J$ Pain Symptom Manage. 2012;43(2):244-52. doi: 10.1016/j. jpainsymman.2011.03.019.

130. Campos RJ, Maciel CT, Cesca MG, Leite IC. Voice analysis after cancer treatment with organ preservation. Head Neck Oncol. 2011;3(1):19. doi: 10.1186/1758-3284-3-19.

131. Naidu MUR, Ramana GV, Rani PU, Mohan IK, Suman A, Roy P. Chemotherapy-induced and/or radiation therapyinduced oral mucositis-complicating the treatment of cancer. Neoplasia. 2004;6(5):423-31. doi: 10.1593/ neo.04169.

132. Al-Dasooqi N, Sonis ST, Bowen JM, Bateman E, Blijlevens $\mathrm{N}$, Gibson RJ, et al. Emerging evidence on the pathobiology of mucositis. Supportive Care Cancer. 2013;21(7):2075-83. doi: 10.1007/s00520-013-1810-y.

133. Bjordal JM, Bensadoun RJ, Tunèr J, Frigo L, Gjerde K, Lopes-Martins RA. A systematic review with meta-analysis of the effect of low-level laser therapy (LLLT) in cancer therapy-induced oral mucositis. Supportive Care Cancer. 2011;19(8):1069-77. doi: 10.1007/s00520-011-1202-0.

134. Bensadoun RJ, Nair RG. Low-level laser therapy in the prevention and treatment of cancer therapy-induced mucositis: 2012 state of the art based on literature review and meta-analysis. Curr Opin Oncol. 2012;24(4):363-70. doi: 10.1097/ CCO.0b013e328352eaa3.

135. Kim JH, Kolozsvary AJ, Jenrow KA, Brown SL. Mechanisms of radiation-induced skin injury and implications for future clinical trials. Int J Radiat Biol. 2013;89(5):311-8. doi: 10.3109/09553002.2013.765055.

136. Rezvani M, Robbins M, Hopewell J, Whitehouse E. Modification of late dermal necrosis in the pig by treatment with multi-wavelength light. Br J Radiol. 1993;66(782):1459. doi: 10.1259/0007-1285-66-782-145.

137. Bensadoun RJ. Photobiomodulation or low-level laser therapy in the management of cancer therapy-induced mucositis, dermatitis and lymphedema. Curr Opin Oncol. 2018;30(4):226-32. doi: 10.1097/CCO.0000000000000452.

138. Russi EG, Corvo R, Merlotti A, Alterio D, Franco P, Pergolizzi S, et al. Swallowing dysfunction in head and neck cancer patients treated by radiotherapy: review and recommendations of the supportive task group of the Italian Association of Radiation Oncology. Cancer Treat Rev. 2012;38(8):1033-49. doi: 10.1016/j.ctrv.2012.04.002.

139. Cullins MJ, Connor NP. Reduced tongue force and functional swallowing changes in a rat model of post stroke dysphagia. Brain Res. 2019;1717:160-6. doi: 10.1016/j. brainres.2019.04.023.

140. El Mobadder M, Farhat F, El Mobadder W, Nammour S. Photobiomodulation Therapy in the Treatment of Oral Mucositis, Dysphagia, Oral Dryness, Taste Alteration, and Burning Mouth Sensation Due to Cancer Therapy: A Case Series. Int J Environ Res Public Health. 2019 Jan;16(22):4505. doi:10.3390/ijerph16224505

141. El Mobadder M, Farhat F, Nammour S. Photobiomodulation therapy in the treatment of chronic dysphagia post hormonal therapy in a breast cancer patient. Dent J (Basel). 2019;7(2):53. doi: 10.3390/dj7020053.

142. Huang SH, Hahn E, Chiosea SI, Xu ZY, Li JS, Shen L, et al. The role of adjuvant (chemo-) radiotherapy in oral cancers 
in the contemporary era. Oral Oncol. 2020;102:104563. doi: 10.1016/j.oraloncology.2019.104563.

143. Geiger JL, Adelstein DJ. Chemotherapy in the definitive management of oral cancers: Where do we stand today? Oral Oncol. 2020;102:104584. doi: 10.1016/j. oraloncology.2020.104584.

144. O’Dell K, Sinha U. Osteoradionecrosis. Oral Maxillofac Surg Clin North Am. 2011;23(3):455-64. doi: 10.1016/j. coms.2011.04.011.

145. Harris M. The conservative management of osteoradionecrosis of the mandible with ultrasound therapy. Br J Oral Maxillofac Surg. 1992;30(5):313-8. doi: 10.1016/0266-4356(92)90181-h.

146. Oh HK, Chambers MS, Martin JW, Lim HJ, Park HJ. Osteoradionecrosis of the mandible: treatment outcomes and factors influencing the progress of osteoradionecrosis. J Oral Maxillofac Surg. 2009;67(7):1378-86. doi: 10.1016/j. joms.2009.02.008.

147. Magalhães IA, Forte CPF, Viana TSA, Teófilo CR, Verde RDM, Magalhães DP, et al. Photobiomodulation and antimicrobial photodynamic therapy as adjunct in the treatment and prevention of osteoradionecrosis of the jaws: a case report. Photodiagnosis Photodyn Ther. 2020;31:101959. doi: 10.1016/j.pdpdt.2020.101959.

148. Chow R. Low level laser therapy-mechanism of action: analgesia. In: Freitas PM, Simões A, editors. Lasers in Dentistry: Guide for clinical practice. Weinheim: WileyBlackwell; 2015. p. 34-9.

149. Ribeiro GH, Minamisako MC, da Silva Rath IB, Santos AMB, Simões A, Pereira KCR, et al. Osteoradionecrosis of the jaws: case series treated with adjuvant low-level laser therapy and antimicrobial photodynamic therapy. $J$ Appl Oral Sci. 2018;26:e20170172. doi: 10.1590/1678-77572017-0172.

150. Sierra SO, Deana AM, Ferrari RAM, Albarello PM, Bussadori SK, Fernandes KPS. Effect of low-level laser therapy on the post-surgical inflammatory process after third molar removal: study protocol for a double-blind randomized controlled trial. Trials. 2013;14(1):373. doi: 10.1186/1745-6215-14-373.

151. Ferrante M, Petrini M, Trentini P, Perfetti G, Spoto G. Effect of low-level laser therapy after extraction of impacted lower third molars. Lasers Med Sci. 2013;28(3):845-9. doi: 10.1007/s10103-012-1174-4.

152. Barbosa D, Villaverde AGJB, LoschiavoArisawa EÂ, de Souza RA. Laser therapy in bone repair in rats: analysis of bone optical density. Acta Ortop Bras. 2014;22(2):71-4. doi: 10.1590/1413-78522014220200438.

153. Chang WD, Wu JH, Wang HJ, Jiang JA. Therapeutic outcomes of low-level laser therapy for closed bone fracture in the human wrist and hand. Photomed Laser Surg. 2014;32(4):212-8. doi: 10.1089/pho.2012.3398.

154. Lucke LD, Bortolazzo FO, Theodoro V, Fujii L, Bombeiro
AL, Felonato M, et al. Low-level laser and adipose-derived stem cells altered remodelling genes expression and improved collagen reorganization during tendon repair. Cell Prolif. 2019;52(3):e12580. doi: 10.1111/cpr.12580.

155. Badawy FA, ElSayed WH, Saidi AA, Wadee AN, Al Balah OF, Abd El Azim ER. Effect of different doses of lowintensity laser therapy on total active range of motion after hand flexor tendon repair. J Med Sci Res. 2019;2(1):29-35. doi: 10.4103/JMISR.JMISR_5_19.

156. Tezcan S, Ulu Ozturk F, Uslu N, Nalbant M, Umit Yemisci O. Carpal tunnel syndrome: evaluation of the effects of low-level laser therapy with ultrasound strain imaging. J Ultrasound Med. 2019;38(1):113-22. doi: 10.1002/ jum.14669.

157. Xuan W, Agrawal T, Huang L, Gupta GK, Hamblin MR. Low-level laser therapy for traumatic brain injury in mice increases brain derived neurotrophic factor (BDNF) and synaptogenesis. J Biophotonics. 2015;8(6):502-11. doi: 10.1002/jbio.201400069.

158. Karu T. Primary and secondary mechanisms of action of visible to near-IR radiation on cells. J Photochem Photobiol B. 1999;49(1):1-17. doi: 10.1016/ S1011-1344(98)00219-X.

159. Bernstein EF. Hair growth induced by diode laser treatment. Dermatol Surg. 2005;31(5):584-6. doi: 10.1111/ j.1524-4725.2005.31168.

160. Schulz KF, Altman DG, Moher D. CONSORT 2010 statement: updated guidelines for reporting parallel group randomised trials. BMC Med. 2010;8(1):18. doi: 10.1186/1741-7015-8-18.

161. Schindl M, Kerschan K, Schindl A, Schön H, Heinzl $\mathrm{H}$, Schindl L. Induction of complete wound healing in recalcitrant ulcers by low-intensity laser irradiation depends on ulcer cause and size. P Photodermatol Photoimmunol Photomed. 1999;15(1):18-21. doi: 10.1111/ j.1600-0781.1999.tb00047.x.

162. Vinck EM, Cagnie BJ, Cornelissen MJ, Declercq HA, Cambier DC. Increased fibroblast proliferation induced by light emitting diode and low power laser irradiation. Lasers Med Sci. 2003;18(2):95-9. doi: 10.1007/s10103-003-0262-x.

163. Pinheiro ALB, Pozza DH, Oliveira MGD, Weissmann R, Ramalho LMP. Polarized light (400-2000 nm) and non-ablative laser $(685 \mathrm{~nm})$ : a description of the wound healing process using immunohistochemical analysis. Photomed Laser Surg. 2005;23(5):485-92. doi: 10.1089/ pho.2005.23.485.

164. Brignardello-Petersen R, Carrasco-Labra A, Araya I, Yanine N, Beyene J, Shah PS. Is adjuvant laser therapy effective for preventing pain, swelling, and trismus after surgical removal of impacted mandibular third molars? A systematic review and meta-analysis. J Oral Maxillofac Surg. 2012;70(8):1789-801. doi: 10.1016/j.joms.2012.01.008. 